\title{
Sternomental Displacement and Neck Circumference. A New Look for the Neck as a Difficult Airway Predictor in Obese Surgical Patients. A Cohort Study
}

\author{
Antony Gorgy \\ Cairo University \\ Abeer Ahmed ( $\boldsymbol{\sigma}$ abeer_ahmed@kasralainy.edu.eg ) \\ Cairo University - Egypt \\ Mohamed Atef \\ Cairo University \\ Nevan El Mekawy \\ Cairo University \\ Heba Nagy \\ Cairo University \\ Wael Sami \\ Cairo University
}

\section{Research Article}

Keywords: Difficult laryngoscopy, difficult intubation, sternomental displacement, neck circumference, obesity

Posted Date: February 1st, 2022

DOl: https://doi.org/10.21203/rs.3.rs-1251511/v1

License: (a) (i) This work is licensed under a Creative Commons Attribution 4.0 International License. Read Full License 


\section{Abstract \\ Background}

Sternomental displacement (SMDD) is a surrogate indicator for cervical spine (C-spine) mobility. SMDD revealed good potentials to predict difficult airway, but its validity in obese patients is not evident. This study assessed the performance of SMDD with neck circumference (NC) in predicting difficult airway in obese surgical patients.

\section{Methods}

The study involved 135 adult patients with $\mathrm{BMI} \geq 35 \mathrm{~kg} / \mathrm{m}^{2}$, scheduled for elective surgeries under general anesthesia with endotracheal tubes (ETT) inserted using Macintosh laryngoscopes. The airway was assessed using SMDD, NC, and Modified Malampati test (MMT). Difficult laryngoscopy view (DLV) was defined as Cormack-Lehane (C-L) grade $\geq 3$. The accuracy of the SMDD in predicting DLV was set as the primary endpoint, while the accuracy of the SMDD compared to that of NC, MMT, and NC/SMDD ratio in predicting difficult airway was set as the secondary endpoint.

\section{Results}

The DLV cases were 28 of 135 (20.7\%), with a mean body mass index (BMI) of $41.1 \pm 3.3 \mathrm{~kg} / \mathrm{m}^{2}$. SMDD < $5 \mathrm{~cm}$ and NC $>43 \mathrm{~cm}$ could predict DLV with an area under the receiver operating characteristic curve (AUROC) of 0.97 and 0.83 respectively. SMDD and NC revealed a good negative correlation $(r=-0.6 ; 95 \% \mathrm{Cl}=$ 0.7 to $0.4 ; p=0.0001$ ). The NC/SMDD ratio had the best predition for DLV (AUROC of 0.98 at a cut-off value > 7.8).

\section{Conclusion}

In obese surgical patients, the SMDD and NC/SMDD ratio are excellent predictors for DLV when the cut-off values are $<5 \mathrm{~cm}$ and $>7.8$, respectively.

\section{Trial registration}

: ClinicalTrials.gov identifier: ID: NCT04524546 Registered in August 2020.

\section{Introduction}

The difficulty securing or maintaining the airway remains a significant cause of anesthesia-related hypoxic brain damage and death. Identifying situations and patients at risk of airway management problems is the key to optimal care and has been the focus of numerous publications. ${ }^{1}$ 
Major airway complications in intensive care units and operating rooms involving obese patients are $47 \%$ and $40 \%$, respectively. ${ }^{2-4}$ Obesity is defined as body mass index (BMI) $>30 \mathrm{~kg} / \mathrm{m}^{2}$. Obesity causes abnormal fat distribution around the cervical region, increasing neck circumference (NC). The short neck in obese patients limits cervical spine (C-spine) mobility. Increased NC and limited C-spine mobility were reported to be independent predictors of the difficult airway. ${ }^{5,6}$

Sternomental displacement (SMDD) is a relatively new airway measure that represents the difference between the sternomental distance (SMD) that is measured while the head is extended on the neck (SMDextension) and while the head is in a neutral position (SMD-neutral). The SMDD is a surrogate indicator of Cspine mobility, and it was proved to be a good objective predictor for difficult Laryngoscopy view (DLV) in adult patients, and its predictive ability was increased when combined with NC. 7

To the best of our knowledge, the validity of the SMDD was not previously assessed in obese patients. Therefore, this study hypothesized that SMDD could be a good objective predictor for difficult airway in obese patients undergoing general anesthesia (GA). The accuracy of the SMDD as a predictor for DLV was set as the primary endpoint, and to compare the accuracy of SMDD to that of NC, NC/SMDD ratio, BMI, and Modified Malampati test (MMT), in predicting DLV and difficult intubation (DI) were set as the secondary endpoints.

\section{Materials And Methods}

This observational cohort study was conducted in Cairo University hospitals, from September 2020 till July 2021, after being approved by the Research Ethics Committee of the Kasr Alainy Faculty of Medicine (ID: MS141-2020, on May 2020, email: kasralainirec@gmail.com). The study was registered on ClinicalTrials.gov (NCT04524546) in August 2020 before patients' enrollment. All methods were carried out in accordance with relevant guidelines and regulations. The reporting of this study conformed to the Accurate Reporting of Diagnostic tests (STARD) guidelines. Written informed consent was obtained from all patients.

We inrolled 135 consecutive patients aged $>18$ years, ASA physical status II \& III, with BMI $\geq 35 \mathrm{~kg} / \mathrm{m}^{2}$, who were scheduled for elective surgeries under GA with endotracheal tubes (ETT) inserted using Macintosh laryngoscopes. Patients with craniofacial abnormalities, lesions or scars in the head and neck, previous cervical spine surgeries, and those who needed awake intubation were excluded.

The airway examination was performed preoperatively by two research team members who have not been involved in assessing the laryngeal view and endotracheal intubation. The following tests were accomplished; Sternomental displacement (SMDD): ${ }^{7}$ while the patient's head was neutral, SMD-neutral was measured using tape as the distance between the upper borders of the manubrium sterni and the mentum. The SMD-extension was then measured in the same way with the head extended on the neck. The difference between SMD-extension and SMD-neutral was then calculated as SMDD. Neck circumference (NC): ${ }^{8}$ was measured using tape at the level of the thyroid cartilage. Modified Mallampati test (MMT): The proper classification was recorded while the patient was sitting in a neutral position. ${ }^{9}$ During the statistical analysis, $\mathrm{NC/}$ SMDD ratio was calculated. 
In the operating room, the patient was positioned in the ramped position (by placing blankets under the patient's upper body and head until a horizontal alignment was achieved between the external auditory meatus and the sternal notch). ${ }^{10}$ Intravenous access was secured, and Ringer acetate solution was started. The basic monitors in the form of non-invasive blood pressure, pulse oximeter, and electrocardiogram were connected. The patients were then pre-oxygenated for 3 minutes using $100 \%$ oxygen. Anesthesia was induced intravenously using fentanyl $1 \mu \mathrm{g} / \mathrm{kg}$, propofol $1.5-2 \mathrm{mg} / \mathrm{kg}$, and succinylcholine $1 \mathrm{mg} / \mathrm{kg}$, depending on the lean body weight. Mask ventilation was maintained until complete muscle relaxation was achieved guided by a peripheral nerve stimulator. Our team's two most senior investigators assessed the laryngoscopic view and completed the endotracheal intubation using a Macintosh laryngoscope. These investigators were blinded to the preoperative airway examination results. The possible best laryngeal view that was obtained and its grade was recorded using Cormack-Lehane (C-L) grades as grade I: the vocal cords are completely visible, grade II: only the arytenoids are visible, grade III: only the epiglottis is visible, and grade IV: the epiglottis is not visible. ${ }^{11}$ The external neck manipulation was used to get the best view. In our study, grades I \&II were categorized as easy laryngoscopy, and grades III and IV were categorized as DLV. Difficult tracheal intubation (DI) was defined as the proper insertion of the ETT using conventional laryngoscopy that required more than two attempts or more than 10 minutes. Failed conventional tracheal intubation was defined as intubation requiring an alternative technique to secure the airway. ${ }^{12}$ The accuracy of the SMDD in predicting DLV with a calculated cut-off value was analyzed as the primary endpoint, while the accuracy of SMDD compared to that of $\mathrm{NC}, \mathrm{NC} / \mathrm{SMDD}$ ratio, $\mathrm{BMI}$, and MMT in predicting DLV and DI were set as secondary endpoints.

\section{Statistical analysis:}

The sample size was calculated using MedCalc software to detect the area under the receiver operating characteristic curve (AUROC) for SMDD of 0.7 with null hypothesis AUROC of 0.5 . We considered that the DLV rate in obese patients would be $23 \%$; ${ }^{13}$ and we calculated a minimum number of 122 patients (with at least $28 \mathrm{DL}$ cases) for a study power of $90 \%$ and an alpha error of 0.05 . the number was increased to 135 for possible dropouts.

Statistical analysis was performed using the program IBM SPSS version 23 (Chicago, IL, USA). The normality of data distribution was assessed using the Kolmogorov-Smirnov and Shapiro-Wilk tests. Continuous quantitative data was expressed for all statistical comparisons as means and standard deviations (SD) or median and range as appropriate, while qualitative categorical data was expressed as a percentage or ratio. Normally distributed data were compared using Student's t-test, while non-normally distributed data were compared using the Mann-Whitney test or the Kruskal-Wallis test as appropriate. Spearman's rank correlation coefficient evaluated the possible relationship between the SMDD and NC. A P-value $<0.05$ was considered statistically significant. The MedCalc software was used to construct the receiver operating characteristics (ROC) curve to determine the accuracy of SMDD, NC, MMT, NC, and NC/SMDD for predicting difficult airway (DLV and DI). For this purpose, binary variables were created (easy versus difficult laryngology and easy versus difficult intubation). The ideal cut-off values for all the tested variables were determined using the Youden index. In addition, the sensitivity, specificity, positive predictive value (PPV), and negative predictive value (NPV) were calculated. A P-value $<0.05$ was considered statistically significant. 


\section{Results}

In this study, a total of 135 patients (76 females and 59 males) met our inclusion criteria and were enrolled and completed the study. Their mean age was $38.6 \pm 8.8$ years, BMI $41.1 \pm 3.3 \mathrm{~kg} / \mathrm{m}^{2}$ with ASA classification II/III was $111 / 24$. The SMDD was $5.5 \pm 0.7 \mathrm{~cm}$, and the NC was $42.1 \pm 2.3 \mathrm{~cm}$. The cases that encountered DLV were $28 / 135$ (20.7\%), while those who encountered DI were 10/135 (7.4\%). No failed endotracheal intubation cases.

The patients were divided according to their laryngoscopic view into the easy laryngoscopy group $(n=107)$ and the difficult laryngoscopy group $(n=28)$. The difficult laryngoscopy group revealed a significantly smaller SMDD and a larger NC than that in the easy laryngoscopy group $(4.4 \pm 0.5$ versus $5.7 \pm 0.4 \mathrm{~cm} ; p=0.001$ and $41.2 \pm 2.2$ versus $45.1 \pm 3.2 \mathrm{~cm} ; p=0.001$ respectively). The NC/SMDD ratio was significantly higher in the difficult laryngoscopy group than the easy laryngoscopy group $(10.3 \pm 1.5$ versus $7.2 \pm 0.3 ; p=0.001$, respectively). The MMT was significantly higher in the difficult laryngoscopy group, while the BMI was comparable in both groups. (Table 1) The patients were then divided according to the intubation condition into easy intubation ( $n=125)$ and difficult intubation $(n=10)$ groups. The SMDD was significantly smaller, and the NC was significantly larger in patients with difficult intubation compared to those with easy intubation (4.4 \pm 0.5 versus $5.5 \pm 0.6 \mathrm{~cm}, p=0.001$ and $45 \pm 4$ versus $41.8 \pm 2.7 \mathrm{~cm}, p=0.001$ respectively). NC/SMDD ratio was significantly higher in the difficult intubation group than the easy intubation group (10.5 \pm 1.8 versus $7.7 \pm 1.4 \mathrm{~cm} ; p=0.001$, respectively). The BMI and MMT were both higher in patients with difficult intubation. (Table-1)

Table 1

Airway Characteristics according to laryngoscopic view and intubation conditions:

\begin{tabular}{|c|c|c|c|c|c|c|}
\hline \multirow[t]{3}{*}{ Airway measure } & \multicolumn{3}{|c|}{ Laryngoscopic view } & \multicolumn{3}{|c|}{ Intubation conditions } \\
\hline & Easy & Difficult & $P$ & Easy & Difficult & $P$ \\
\hline & $n=107$ & $\mathrm{n}=\mathbf{2 8}$ & value & $n=125$ & $n=10$ & value \\
\hline Age (years) & $39.1 \pm 9.3$ & $36.9 \pm 6.5$ & 0.2 & $38.6 \pm 9.1$ & $39.4 \pm 3.6$ & 0.3 \\
\hline $\operatorname{BMI}\left(\mathrm{kg} / \mathrm{m}^{2}\right)$ & $40.8 \pm 3.4$ & $42.2 \pm 2.3$ & 0.3 & $40.8 \pm 3.2$ & $43.1 \pm 2.4$ & 0.03 \\
\hline MMT (class) & $2(1-3)$ & $3(2-4)$ & 0.001 & $2(1-4)$ & $3(2-4)$ & 0.02 \\
\hline SMDD (cm) & $5.7 \pm 0.4$ & $4.4 \pm 0.5$ & 0.001 & $5.5 \pm 0.6$ & $4.4 \pm 0.5$ & 0.001 \\
\hline $\mathrm{NC}(\mathrm{cm})$ & $41.2 \pm 2.2$ & $45.1 \pm 3.2$ & 0.001 & $41.8 \pm 2.7$ & $45 \pm 4$ & 0.001 \\
\hline NC/SMDD ratio & $7.2 \pm 0.3$ & $10.3 \pm 1.5$ & 0.001 & $7.7 \pm 1.4$ & $10.5 \pm 1.8$ & 0.001 \\
\hline
\end{tabular}


Table 2

Predictive ability of BMI, MMT, SMDD, NC, and NC/SMDD ratio for difficult laryngoscopy view (DLV):

\begin{tabular}{|c|c|c|c|c|c|c|c|c|}
\hline & AUROC & $95 \% \mathrm{Cl}$ & $\begin{array}{l}P \\
\text { value }\end{array}$ & Sensitivity & Specificity & $\begin{array}{l}\mathbf{+ v} \\
\text { predictive }\end{array}$ & $\begin{array}{l}\text {-ve } \\
\text { predictive }\end{array}$ & $\begin{array}{l}\text { Cut- } \\
\text { off } \\
\text { value }\end{array}$ \\
\hline BMI & 0.65 & $\begin{array}{l}0.56- \\
0.73\end{array}$ & 0.005 & $79 \%$ & $57 \%$ & $33 \%$ & $91 \%$ & $\begin{array}{l}>41 \\
\mathrm{~kg} / \mathrm{m}^{2}\end{array}$ \\
\hline MMT & 0.94 & $0.88-.97$ & 0.001 & $86 \%$ & $94 \%$ & $80 \%$ & $96 \%$ & $>2$ \\
\hline SMDD & 0.97 & $\begin{array}{l}0.93- \\
0.99\end{array}$ & 0.001 & $96 \%$ & $95 \%$ & $82 \%$ & $99 \%$ & $<5 \mathrm{~cm}$ \\
\hline NC & 0.83 & $\begin{array}{l}0.75- \\
0.86\end{array}$ & 0.001 & $75 \%$ & $87 \%$ & $60 \%$ & $93 \%$ & $>43 \mathrm{~cm}$ \\
\hline $\begin{array}{l}\text { NC/SMDD } \\
\text { ratio }\end{array}$ & 0.98 & $\begin{array}{l}0.94- \\
0.99\end{array}$ & 0.001 & $99 \%$ & $99 \%$ & $86 \%$ & $100 \%$ & $>7.8$ \\
\hline
\end{tabular}

Table 3

Predictive ability of BMI, MMT, SMDD, NC, and NC/SMDD ratio for difficult intubation (DI):

\begin{tabular}{|lllllllll|}
\hline & AUROC & $\begin{array}{l}95 \% \\
\text { Cl }\end{array}$ & $\begin{array}{l}\boldsymbol{P} \\
\text { value }\end{array}$ & Sensitivity & Specificity & $\begin{array}{l}+\mathbf{v} \\
\text { predictive }\end{array}$ & $\begin{array}{l}\text {-ve } \\
\text { predictive }\end{array}$ & $\begin{array}{l}\text { Cut-off } \\
\text { value }\end{array}$ \\
\hline BMI & 0.72 & $\begin{array}{l}0.64- \\
0.79\end{array}$ & 0.001 & $60 \%$ & $80 \%$ & $20 \%$ & $96 \%$ & $\begin{array}{l}>43 \\
\mathrm{~kg} / \mathrm{m}^{2}\end{array}$ \\
\hline MMT & 0.91 & $\begin{array}{l}0.85- \\
0.95\end{array}$ & 0.001 & $90 \%$ & $83 \%$ & $32 \%$ & $99 \%$ & $>2$ \\
\hline SMDD & 0.93 & $\begin{array}{l}0.87- \\
0.97\end{array}$ & 0.001 & $99 \%$ & $86 \%$ & $37 \%$ & $99 \%$ & $<4.8 \mathrm{~cm}$ \\
\hline NC & 0.73 & $\begin{array}{l}0.64- \\
0.80\end{array}$ & 0.02 & $70 \%$ & $78 \%$ & $20 \%$ & $97 \%$ & $>43 \mathrm{~cm}$ \\
$\begin{array}{l}\text { NC/SMDD } \\
\text { ratio }\end{array}$ & 0.92 & $\begin{array}{l}0.86- \\
0.96\end{array}$ & 0.001 & $90 \%$ & $83 \%$ & $30 \%$ & $99 \%$ & $>8.8$ \\
\hline $\begin{array}{l}\text { AUROC curve: area under the receiver operating characteristic curve; BMl: body mass index; MMT: } \\
\text { modified Mallampati test; SMDD: Sternomental displacement; NC: neck circumference. }\end{array}$ & \\
\hline
\end{tabular}

The possible correlation between SMDD and NC revealed a good negative correlation $(r=-0.6 ; 95 \% \mathrm{Cl}=0.7$ to $0.4 ; p=0.0001$ ). (Figure 1). The BMI, SSMD, NC, NC/SMDD, and MMT were used to construct a ROC Curve to assess their ability to predict cases with DLV (Figure-2). The AUROC curve, sensitivity, specificity, PPV, NPV, and the cut-off value for all tested variables are presented in (Table-2). The same parameters were used to construct another ROC curve to assess their ability to predict cases with DI (Figure-3). The AUROC, sensitivity, 
specificity, PPV, NPP, and the cut-off value for all parameters are presented in (Table-3). Both SMDD and NC/SMDD showed a very high predictive ability for both DLV and DI.

\section{Discussion}

The main findings of our study were that in obese patients undergoing GA with ETT inserted using Macintosh laryngoscope, SMDD was a good predictor of DLV and DI. A large NC was a fair predictor, but the NC/SMDD ratio provided an excellent prediction of DLV and DI. Despite the increased BMI in patients with DLV, BMI showed a weak predictive ability.

The C-spine mobility is a fundamental component in determining the ease of laryngeal exposure during direct laryngoscopy and endotracheal intubation. During direct laryngoscopy, the C-spine extension occurred mainly at the occipito-atlanto-axial (OAA) complex with minimal movement at the level of subaxial cervical segments. ${ }^{14} \mathrm{~A}$ patient may be difficult to intubate because the head cannot be sufficiently extended on the neck, as in patients with a cervical spine injury, rheumatoid arthritis, and ankylosing spondylitis. However, it has been demonstrated that even a simple C-spine extension could improve the visualization of the glottic opening, so the sniffing position was shown to effectively improve the laryngeal view primarily due to its ability to facilitate the angulation and extension at the level of the OAA complex. ${ }^{14}$ In 2008 , a retrospective study was conducted by Mashour GA et al., ${ }^{15}$ including the records of the preoperative airway evaluation of 14053 surgical patients. The authors identified that $8.1 \%$ of patients were reported to have limited C-spine mobility, and the incidences of difficult laryngoscopy and difficult intubation were twice more than that in normal patients.

The degree of C-spine mobility is expressed either as a full range of neck movement, from maximum flexion to maximum extension, or as the degree of either extension or flexion. Several methods were described to measure the degree of $\mathrm{C}$-spine movement. Wilson et al. ${ }^{16}$ have described how to measure the full range of $\mathrm{C}$ spine mobility by using a pencil applied vertically on the forehead that moves from maximum flexion to maximum extension, and they identified three levels of C-spine mobility; $<80^{\circ}, 80-90^{\circ}$, and $>90^{\circ}$. Difficult laryngoscopy could be expected when the range of C-spine mobility is less than $80^{\circ}$. Some studies used a goniometer or clinometer for their measurements. ${ }^{17,18}$ In a previous study that included 190 patients in whom the clinometer measured neck extension and flexion, the study revealed that difficult laryngoscopy should be expected when the neck extension from the neutral position is $\leq 37.5^{\circ} .{ }^{18}$ In the previously mentioned techniques, ${ }^{16-18}$ the $\mathrm{C}$-spine mobility was described as angles' degrees.

The SMDD is considered a surrogate indicator of C-spine mobility. Prakash S et al., in $2017,{ }^{7}$ studied the SMDD in 610 surgical patients, with a mean BMI of $23.68 \pm 4.87 \mathrm{~kg} / \mathrm{m}^{2}$. SMDD showed a sensitivity of $70 \%$ and specificity of $53 \%$ for predicting DLV at a cut-off value $\leq$ of $5.25 \mathrm{~cm}$. The authors concluded that SMDD provides a rapid, simple, objective measure for predicting patients at risk of DLV. Another recent study conducted by Kopanaki E et al. in $2020{ }^{19}$ included 221 surgical patients with a mean BMI of $27.1 \pm 5.1 \mathrm{~kg} / \mathrm{m}^{2}$. The authors measured the SMD ratio (SMDR), which represents the ratio between SMD in extension to SMD in neutral neck positions. The authors noticed a negative correlation between the SMDR and the C-L grade. A SMDR below 1.55 was associated with DLV incidence ranging between 33-53\% (C-L III-IV glottic views), while 
a SMDR >1.9 means no likelihood expected DLV. The SMDD and SMDR are easier to measure, and the calculated difference or ratio between two straight lengths might be more accurate than angles' degrees.

Another privilege of both SMDD and SMDR is to avoid using the absolute values of the SMD, which revealed a wide range of cut-off values for predicting DLV as $12.5 \mathrm{~cm},{ }^{20} 13.5 \mathrm{~cm},{ }^{21}$, and $15 \mathrm{~cm}{ }^{22}$ due to the anthropometric differences among the population. Our study is the first study that assessed the performance of SMDD as a predictor of difficult airway in the obese population, with promising results for predicting both DLV and DI. Furthermore, the high specificity (95\%) and high NPV (99\%) for predicting DLV means that $99 \%$ for tested cases will be easy to intubate when the test is negative.

The role of neck circumference in predicting DLV and DI is still debatable; 6,8 our results revealed a good predictive ability of the NC for DLV with an AUROC of $83 \%, 75 \%$ sensitivity, and $87 \%$ specificity when the cutoff value $>43 \mathrm{~cm}$. This ability is reduced for predicting DI with AUROC of $73 \%, 70 \%$ sensitivity, and $78 \%$ sepcificty at the same cut-off value. In a study by Gonzalez $\mathrm{H}$ et al., ${ }^{6}$ the NC was correlated with DI at cutoff value $>43 \mathrm{~cm}$, with $92 \%$ sensitivity and $84 \%$ specificity. In another study by Eiamcharoenwit $\mathrm{J}$ et al., ${ }^{8}$ the predictive ability of the NC was deficient as the AUROC for DL was $56 \%$ in the study population with MBI $43.1 \pm 3 \mathrm{~m} \mathrm{~kg} / \mathrm{m}^{2}$ and mean NC of $38.0 \pm 3.0 \mathrm{~cm}$. Both studies ${ }^{6,8}$ defined the DI according to the difficult intubation score (DIS). Other studies revealed a positive correlation between NC and the incidence of DLV and DI. The highest ability of NC to predict DLV and DI was achieved at a cut-off value $>50 \mathrm{~cm}$. ${ }^{13,23}$

It was previously concluded that when a single airway test is used, the value of screening for DLV or DI is restricted, and combining individual tests can provide some incremental diagnostic benefits. ${ }^{24}$ Our study assumed that obese patients with both large NC and impaired neck mobility would be more difficult to intubate when compared with patients with large NC or impaired neck mobility alone. The new predictor, NC/SMDD ratio, provided an excellent predictive ability for DLV and DI. The NC/SMDD ratio revealed an AUROC of $98 \%$ with $99 \%$ sensitivity and $99 \%$ specificity at a cut-off value $>7.8$ for predicting DLV and an AUROC of $92 \%$ with $90 \%$ sensitivity and $83 \%$ sepcificty at a cut-off value $>8.8$ for predicting DI. A study by Kim WH et al. ${ }^{25}$ assumed that NC and Thyromental (TMD) could represent thick and short necks characters, respectively; therefore, authors provided NC/TMD ratio as a new predictor for DI with a better predictive ability compared to other established indices.

Because difficult laryngoscopy is more common than difficult intubation, it was chosen as the primary outcome in our study. Furthermore, difficult laryngoscopy is a direct cause of difficult tracheal intubation, and the degree of the $\mathrm{DL}$ is an important predictor of difficult intubation.

Our study has limitations; we included patients scheduled for elective surgeries, so our results cannot be extrapolated to the emergency, obstetric, or ICU setting. In addition, the influence of age and gender was not taken into considerations. ${ }^{26}$

\section{Conclusion}

In obese surgical patients, the SMDD as a surrogate for neck extension and the NC/SMDD ratio for both NC and extension provide strong DLV and DI predictive abilities. 


\section{List Of Abbreviations}

SMDD: Strernmental displacement: SMDD.

NC: neck circumference.

MMT: modified Malampati test.

C-Spine: Cervical Spine.

BMI: body mass index.

DL: difficult laryngoscopy.

DI: difficult intubation

C-L Grade: Cormack-Lehane grade.

AUROC: area under the receiver operating characteristic curve.

\section{Declarations}

\section{Ethical approval and consent to participate:}

- The study is approved by the Research Ethics Committee of Kasr Alainy Faculty of Medicine, Cairo University (email: kasralainirec@gmail.com ID: MS-141-2020, on May 2020).

- The study was registered on ClinicalTrials.gov identifier: ID: NCT04524546 Registered in August 2020.

- All methods were carried out in accordance with relevant guidelines and regulations. The reporting of this study conformed to the Accurate Reporting of Diagnostic tests (STARD) guidelines.

- Written informed consent was obtained from all patients before they joined the study.

Consent for publication: not applicable

Availability of data and material:

All data associated with this study are present in the manuscript and are available upon request from the corresponding author.

\section{Competing interests:}

The authors declare no conflicts of interest.

\section{Funding:}

No funding, the Cairo University Hospitals resources were used.

\section{Authors contributions:}


AA was responsible for the conception and design of the study, analysis of the data, and writing the manuscript. AG and MA were responsible for preoperative evaluation of the airway. AA and NE were responsible for intraoperative assessment of the laryngeal view and endotracheal intubation. HN and WS shared in data collection and writing the manuscript. All authors had read, revised and approved the final manuscript.

\section{Acknowledgements: N/A}

\section{References}

1. Apfelbaum JI, Hagberg Ca, Caplan Ra, Blitt CD, Connis RT, Nickinovich DG, et al. practice guidelines for management of the difficult airway: An updated report by the American society of anesthesiologists task force on management of the Difficult Airway. Anesthesiology 2013;118: 251-270.

2. Cattano D, Killoran PV, lannucci D, Maddukuri V, Altamirano AV, Sridhar S, et al. Anticipation of the difficult airway: preoperative airway assessment, an educational and quality improvement tool. $\mathrm{Br} \mathrm{J}$ Anaesth 2013;111:276-285.

3. Cook TM, Woodall N, Harper J, Benger J. Major complications of airway management in the UK: results of the Fourth National Audit Project of the Royal College of Anaesthetists and the Difficult Airway Society. Part 2: intensive care and emergency departments. Br J Anaesth 2011;106:632-642.

4. Cook TM, Woodall N, Frerk C. Major complications of airway management in the UK: results of the Fourth National Audit Project of the Royal College of Anaesthetists and the Difficult Airway Society. Part 1: anaesthesia. Br J Anaesth 2011;106:617-631.

5. Salome CM, King GG, Berend N. Physiology of obesity and effects on lung function. J Appl Physiol 2010;108:206-211.

6. Gonzalez H, Minville V, Delanoue K, Mazerolles M, Concina D, Fourcade O. The importance of increased neck circumference to intubation difficulties in obese patients. Anesth Analg 2008; 106: 1132-1136.

7. Prakash S, Mullick P, Bhandari S, Kumar A, Gogia AR, Singh R. Sternomental distance and sternomental displacement as predictor of difficult laryngoscopy and intubation in adult patients. Saudi J Anaesth. 2017;11:273-278.

8. Eiamcharoenwit J, Itthisompaiboon N, Limpawattana P, Suwanpratheep A, Siriussawakul A. The performance of neck circumference and other airway assessment tests for the prediction of difficult intubation in obese parturients undergoing cesarean delivery. Int J Obstet Anesth. 2017 May;31:45-50.

9. Samsoon GL, Young JR. Difficult tracheal intubation: A retrospective study. Anaesthesia 1987;42:487490.

10. Collins JS, Lemmens HJ, Brodsky JB, Brock-Utne JG, Levitan RM. Laryngoscopy and morbid obesity: a comparison of the "sniff" and "ramped" positions. Obes Surg. 2004;14:1171-1175.

11. Cormack RS, Lehane J. Difficult tracheal intubation in obstetrics. Anaesthesia 1984;39:1105-1111.

12. Langeron $O$, Cuvillon $P$, Ibanez-Esteve C, Lenfant F, Riou B, Le Manach Y. Prediction of difficult tracheal intubation: time for a paradigm change. Anesthesiology 2010;117:1223-1233. 
13. Brodsky JB, Lemmens HJM, Brock-Utne JG, Vierra M, Saidman LJ. Morbid obesity and tracheal intubation. Anesth Analg. 2002;94:732-736.

14. Takenaka I, Aoyama K, Iwagaki T, Ishimura H, Kadoya T. The sniffing position provides greater occipitoatlanto-axial angulation than simple head extension: a radiological study. Can J Anaesth. 2007;54:129133.

15. Mashour GA, Stallmer ML, Kheterpal S, Shanks A. Predictors of difficult intubation in patients with cervical spine limitations. Journal of Neurosurgical Anesthesiology 2008; 20: 110-115.

16. Wilson ME, Spiegelhalter D, Robertson JA, Lesser P. Predicting difficult intubation. British Journal of Anaesthesia 1988; 61: 211-216.

17. Chaves TC, Nagamine HM, Belli JFC, de Hannai MCT2, Bevilaqua-Grossi D3, de Oliveira AS. Reliability of fleximetry and goniometry for assessing cervical range of motion among children. Rev Bras Fisioter, São Carlos 2008;12:283-289

18. Salimi, A, Ghanbari M, Razavi SS, Mohajerani SA; Malek S, Mottaghi K. Abstract PR556: Neck Flexion And Extension Measurement, Is That Sensitive Predictor of Difficult to Intubate, Anesth \& Analg 2016;123 (3S): 707.

19. Kopanaki E, Piagkou M, Demesticha T, Anastassiou E, Skandalakis P. Sternomental Distance Ratio as a Predictor of Difficult Laryngoscopy: A Prospective, Double-Blind Pilot Study. Anesth Essays Res. 2020;14:49-55.

20. Savva D. Prediction of difficult tracheal intubation. Br J Anaesth 1994;73:149-153.

21. Al Ramadhani S, Mohamed LA, Rocke DA, Gouws E. Sternomental distance as the sole predictor of difficult laryngoscopy in obstetric anaesthesia. Br J Anaesth 1996;77:312-316.

22. Liaskou C, Vouzounerakis E, Moirasgenti M, Trikoupi A, Staikou C. Anatomic features of the neck as predictive markers of difficult direct laryngoscopy in men and women: A prospective study. Indian $\mathrm{J}$ Anaesth 2014;58:176-182.

23. Abrahams H, Bygrave C, Doyle C, Kendall A, Margarson M. Does neck circumference predict difficult laryngoscopy in morbidly obese patients?, European Journal of Anaesthesiology; 2010; 27:248-249.

24. Shiga T, Wajima Z, Inoue T, Sakamoto A. Predicting difficult intubation in apparently normal patients: a meta-analysis of bedside screening test performance. Anesthesiology 2005; 103: 429-437

25. Kim WH, Ahn HJ, Lee CJ, Shin BS, Ko JS, Choi SJ, et al. Neck circumference to thyromental distance ratio: a new predictor of difficult intubation in obese patients. Br J Anaesth. 2011;106:743-748.

26. Wang T, Sun S, Huang S. The association of body mass index with difficult tracheal intubation management by direct laryngoscopy: a meta-analysis. BMC Anesthesiol. 2018 Jun 30;18(1):79.

\section{Figures}




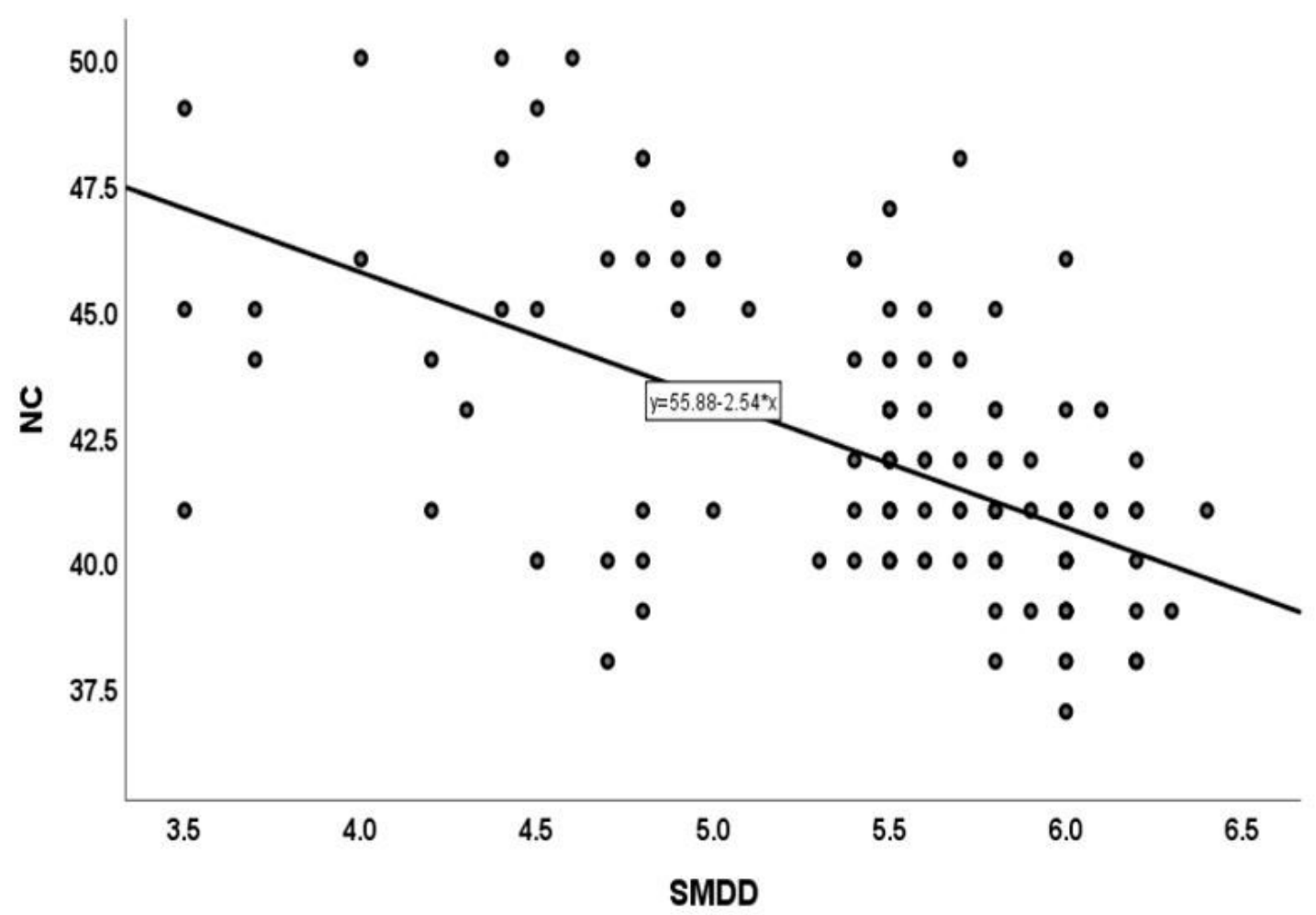

Figure 1

A scattered plot shows the correlation between NC and SMDD. 


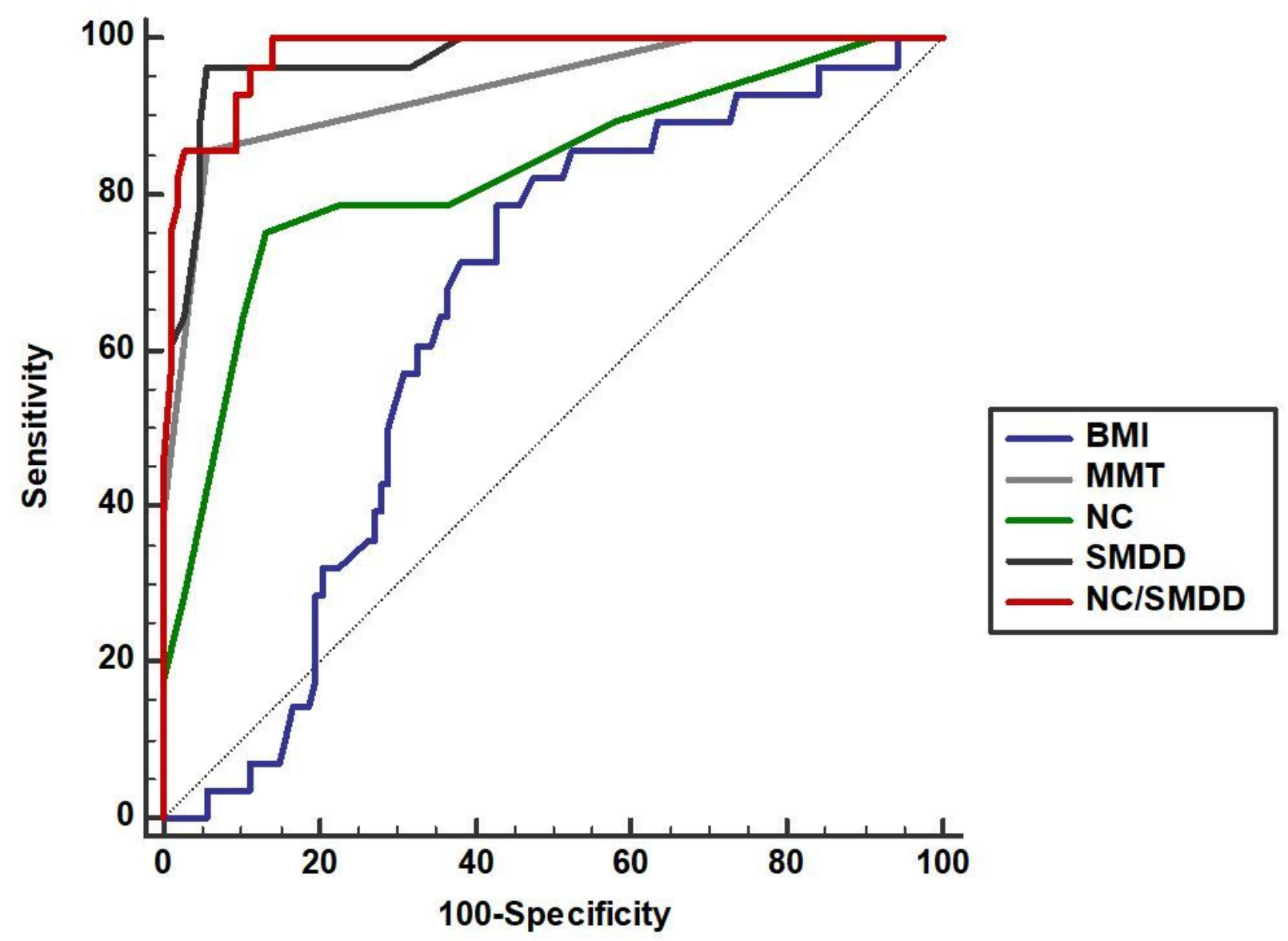

Figure 2

The area under receiver operating characteristics (AUROC) curve to assess the ability of the BMI, MMT, SMDD, NC, and NC/SMDD to predict difficult laryngoscopy View in obese patients undergoing general anesthesia.

BMI, Body Mass Index; SMDD, sternomental displacement, NC, neck circumference 


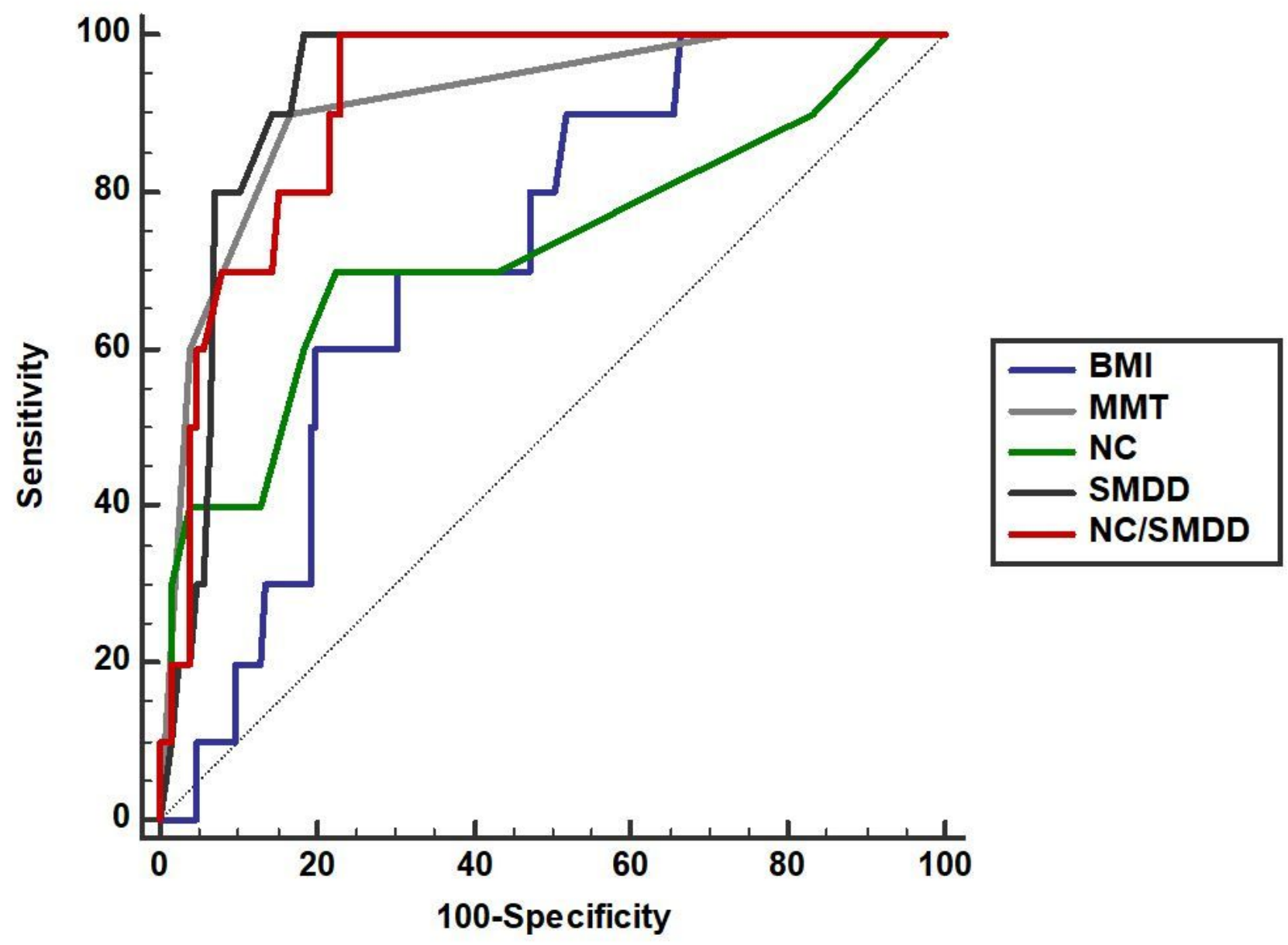

Figure 3

The area under receiver operating characteristics (AUROC) curve to assess the ability of the BMI, MMT, SMDD, $\mathrm{NC}$, and NC/SMD to predict difficult intubation in obese patients undergoing general anesthesia.

BMI, body mass index; SMDD, sternomental displacement, NC, neck circumference 